\title{
ESTIMATIVA DA TEMPERATURA DO SOLO E COMPARAÇÃO DE VARIÁVEIS METEOROLÓGICAS EM ANOS EXTREMOS DE PLUVIOSIDADE EM MOSSORÓ-RN
}

\section{ESTIMATION SOIL TEMPERATURE AND COMPARATIVE OF METEOROLOGICAL VARIABLES IN EXTREME YEARS OF PLUVIOSITY IN MOSSORÓ-RN}

Tecla Ticiane Félix da Silva르, José Espínola Sobrinho², Anna Kézia Soares de Oliveira $^{3}$, Isaac Alves da Silva Freitas ${ }^{4}$, Jhon Lennon Bezerra da Silva ${ }^{5}$, Gabriel Siqueira Tavares Fernandes ${ }^{6}$

DOI: https://doi.org/10.52719/bjas.v1i2.2886

\begin{abstract}
${ }^{1}$ Mestranda em Engenharia Agrícola, Universidade Federal Rural de Pernambtreo, UFRPE. Av. Đ. Manoel de Medeiros, SN; Dois Irmãos, Recife, Pernambuco, Brasil. E-mail:teclaticiane12@hotmail.com; ${ }^{2}$ Docente, Universidade Federal Rural do Semi-Árido, Mossoró-RN, Brasil. E-mail: jespinola@ufersa.edu.br; ${ }^{3}$ Mestranda em Fitotecnia, Universidade Federal Rural do Semi-Árido, Mossoró-RN, Brasil. E-mail: annakezia@ outlook.com; 4 Mestre em Fitoteenia, Universidade Federal Rural do Semi-Árido, Mossoró-RN, Brasil. E-mail: isaacntn@outlook.eom; ${ }^{5}$ Mestre em Engenharia Agrícola, Universidade Federal Rural de Pernambuco, RecifePE, Brasil. E-mail: jhonlennoigt@ hotmail.com; ${ }^{6}$ Mestrando em Engenharia Agrícola, Universidade Federal Rural de Pernambuco, Recife-PE, Brasil, e-mail: agrogabrielt@gmail.com;
\end{abstract}

\section{RESUMO}

A obtenção de informações sobre o comportamento da temperatura em solos sob clima tropical facilita o entendimento das relações solo-planta-atmosfera. O cálculo das temperaturas médias do solo em diferentes profundidades sempre foi problemático, sabendo-se que Mossoró é considerado um polo agrícola, o objetivo principal deste trabalho foi ajustar uma equação que permita estimar a temperatura do solo, em função da temperatura do ar no município de Mossoró-RN. O trabalho foi desenvolvido a partir o de uma estação meteorológica automática pertencente à Universidade Federal Rural do Semiárido, no período de 01/01/2011 a 31/12/2012, sendo o ano de 2011 caracterizado como chuvoso e 2012 como um ano seco na região semiárida. A equação da temperatura do solo estimada, fez-se através da correlação de dados médios diários da temperatura do ar com a temperatura do solo a 02 e $20 \mathrm{~cm}$ processados em planilha eletrônica no Microsoft Excel. Utilizou-se dados médios mensais da radiação global, precipitação pluviométrica, umidade relativa do ar e velocidade do vento, para analisar a influência de cada variável sobre o comportamento da equação estimada. As análises mostraram que as equações ajustadas apresentaram bons resultados para o ano chuvoso de 2011, porém deixou a desejar quando aplicadas ao ano seco de 2012. Quando se especifica um 

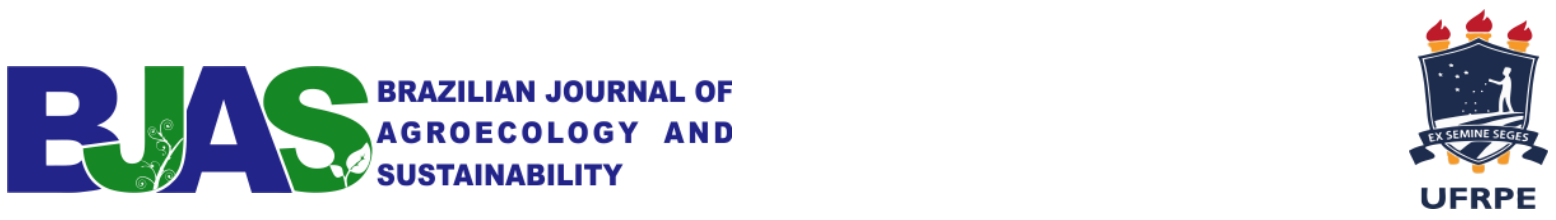

determinado ano, verificou-se melhor ajuste no primeiro semestre quando houve a presença de chuva, enquanto que no segundo semestre seu desempenho foi de regular a fraco. Com relação à profundidade do solo os melhores resultados foram obtidos na profundidade de $2 \mathrm{~cm}$.

Palavras-chave: Meteorologia. Modelagem Agrícola. Técnicas De Cultivo.

\begin{abstract}
Obtaining information on temperature behavior in soils under tropical climate facilitates understanding of soil-plant-atmosphere relationships. The calculation of the average soil temperatures at different depths has always been problematic, since Mossoró is considered an agricultural pole from Mossoró-RN. The work was developed from an automatic weather station belonging to the Federal Rural University of Semiarid, from 01/01/2011 to 12/31/2012, being the year 2011 characterized as rainy and 2012 as a dry year in the semiarid region. The estimated soil temperature equation was made by correlating daily average air temperature data with the soil temperature at 02 and $20 \mathrm{~cm}$ processed in a spreadsheet in Microsoft Excel. Monthly average data of global radiation, rainfall, relative humidity and wind speed were used to analyze the influence of each variable on the behavior of the estimated equation. The analyzes showed that the adjusted equations showed good results for the rainy year 2011, but left to be desired when applied to the dry year 2012. When specifying a particular year, it was better to adjust in the first semester when there was rain, while in the second semester its performance was from regular to weak. Regarding soil depth, the best results were obtained at a depth of 2 $\mathrm{cm}$.
\end{abstract}

Keywords: Meteorology. Agricultural Modeling. Cultivation Techniques.

\title{
1 INTRODUÇÃO
}

O conhecimento do comportamento das variáveis climáticas é de suma importância para o planejamento das atividades agrícolas, principalmente nas regiões do semiárido brasileiro. Os principais elementos climáticos que afetam a produção agrícola são a radiação solar, temperatura e umidade (Ayoade, 2010). A obtenção de informação sobre o comportamento da temperatura em solos sob clima tropical facilita o entendimento da condução térmica para a produtividade agrícola, das relações solo-planta-atmosfera nessas regiões e permite ainda fornecer subsídios para o estudo de técnicas de cultivo ecologicamente adequadas as condições climáticas locais. 

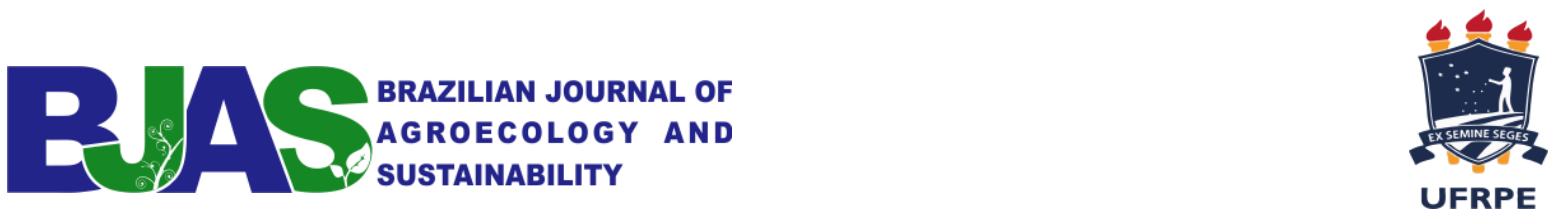

A temperatura do solo tem influência decisiva na formação de uma cultura, graças a interação solo-planta-atmosfera, desde a germinação da planta até o seu estádio final de maturação, pois esta vai agir diretamente na microbiologia do solo, na absorção de água e nutrientes, na evapotranspiração e na umidade que pode favorecer o surgimento de doenças e pragas. A temperatura do solo é uma fração do saldo de radiação absorvida pela superfície, com isso ocorre a elevação do calor dessa superfície, ou seja, o aquecimento, tal qual este aumento dá origem a um gradiente térmico no interior do solo, isto é, a temperatura superficial é imediatamente maior que as camadas inferiores (Tavares, Arruda, \& Silva, 2019). Assim, o aquecimento do solo pode reduzir a própria umidade do solo, que afeta diretamente na respiração dos microrganismos e consequentemente no crescimento radicular das plantas (Bao et al., 2016).

Medeiros, Tavares, Kascar, Silva, \& Silva (2012) verificaram que a temperatura do ar tem um efeito claro no desenvolvimento dos seres vivos, animal e vegetal, sendo necessária a utilização de métodos de estimativas de temperatura confiáveis e mais seguros, para que se possa trabalhar com informações precisas. A verificação da confiabilidade de métodos utilizados para estimar a temperatura média do ar e do solo é importante, visto que estes valores são frequentemente utilizados para avaliar efeitos positivos ou negativos em atividades agrícolas.

A microrregião geográfica da região semiárida de Mossoró que incorpora, além do município que lhe dá nome, os municípios de Areia Branca, Baraúna, Grossos, Serra do Mel e Tibau, é uma das principais microrregiões na produção de importantes produtos da fruticultura, tais como, melão, mamão e melancia. A agricultura desenvolvida na economia espacial de Mossoró, caracteriza-se como forte atividade econômica apropriada como indutora de um desenvolvimento local e regional. A região semiárida de Mossoró é considerada um polo agrícola, nesse sentido, os efeitos climáticos ao longo do ano influenciam diretamente a temperatura do solo o que pode comprometer toda a produção agrícola, apesar das medidas de temperatura do solo a várias profundidades serem rotineiras nas estações meteorológicas, muitas vezes, para estudos específicos, essas informações não estão disponíveis.

O cálculo das temperaturas médias do solo em diferentes profundidades sempre foi problemático, já que as leituras em estações meteorológicas são tradicionalmente feitas em horários fixos, cujas médias aritméticas resultam valores incoerentes, sobretudo para as camadas mais próximas à superfície, onde a oscilação térmica é bem mais acentuada. Dentre os vários métodos desenvolvidos para a estimativa da temperatura do solo usando dados meteorológicos, não foi desenvolvido ainda nenhum que se enquadre às características 
climáticas para região semiárida, tampouco para Mossoró-RN. Em vista disso, considerando o tipo de solo e as condições climáticas da região é necessário um modelo que melhor represente as condições locais.

Diante desse contexto, objetivou-se ajustar um modelo matemático que permita estimar a temperatura do solo em função da temperatura do ar no intuito de otimizar as técnicas de cultivo agrícola para a região semiárida do município de Mossoró-RN. Além também de verificar a influência das diferentes condições climáticas na temperatura do solo e avaliar os parâmetros climáticos que podem interferir na temperatura do solo.

\section{METODOLOGIA}

A presente pesquisa foi realizada em uma região semiárida do Brasil, município de Mossoró, localizado no estado do Rio Grande do Norte, RN, localizado entre os paralelos de $04^{\circ} 90^{\prime} \mathrm{S}$ e $05^{\circ} 50^{\prime} \mathrm{S}$, e entre os meridianos de $37^{\circ} 00^{\prime} \mathrm{W}$ e $37^{\circ} \mathrm{W}$, altitude média de $16 \mathrm{~m}$, a oeste do meridiano de Greenwich. O município de Mossoró situa-se mais especificamente na mesorregião Oeste Potiguar e na microrregião Mossoró, abrangendo uma área de 2.100 km² (Figura 1).

Foram obtidos dados meteorológicos de superfície por meio de uma estação meteorológica automática pertencente à Universidade Federal Rural do Semi-Árido UFERSA, cujas coordenadas geográficas são: 5० 12'48,38' S e 37 18'43,69” W (Figura 1), e altitude de $37 \mathrm{~m}$. A estação gera continuamente dados de superfície oriundos de sensores, através de varreduras dos seus sinais elétricos. Entretanto, a estação foi programada para registrar médias dessas leituras a cada minuto, de forma a se obter leituras de cada sensor por hora. Os dados foram armazenados em um datalogger CR23X que está conectado, via cabo, a um microcomputador PC de escritório, sendo descarregados diariamente. Os dados meteorológicos horários foram convertidos para dados diários.

Figura 1. Mapa espacial de localização da região semiárida, município de Mossoró-RN, Brasil. 


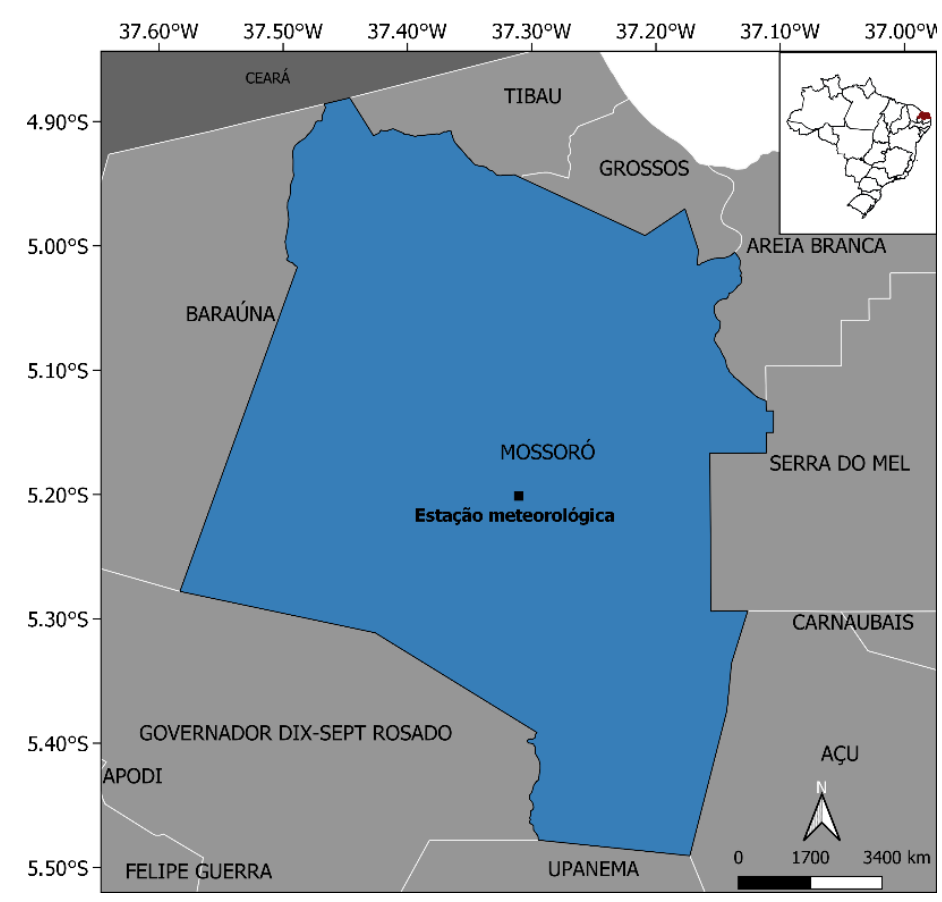

Fonte: Tecla Ticiane.

Os dados horários utilizados na presente pesquisa foram: radiação global ( $\mathrm{MJ} \mathrm{m}^{-2} \mathrm{dia}^{-}$ $\left.{ }^{1}\right)$; temperatura do ar $\left({ }^{\circ} \mathrm{C}\right)$; precipitação pluviométrica $(\mathrm{mm})$; umidade relativa do ar $(\%)$; velocidade do vento $\left(\mathrm{m} \mathrm{s}^{-1}\right)$ e temperatura média do solo a 02 e $20 \mathrm{~cm}\left({ }^{\circ} \mathrm{C}\right)$; referentes ao período de 01 de janeiro de 2011 a 31 de dezembro de 2012. Foi escolhido esse período com base na última década, em que 2011 foi o último ano chuvoso, onde apresentou pluviosidade anual de 956,7 mm (acima da média anual histórica da região), enquanto o ano de 2012 foi considerado o ano mais seco, apresentando pluviosidade anual de 199,4 mm (abaixo da média anual histórica da região). Vale a pena salientar que o ano de 2011 foi um ano de ocorrência de La Niña e 2012 de El Niño, o que explica o comportamento da precipitação pluviométrica nestes anos.

Levando em conta os estudos desenvolvidos por Alfonsi e Sentelhas (1996), seguiu-se a mesma metodologia na presente pesquisa, para estimativa da equação da temperatura do solo em função da temperatura do ar, no entanto, para maior precisão foi utilizado dados diários e não mensais, de acordo com a estatística quanto maior número de observações maior será a precisão do resultado. Para execução dos métodos em estudo foi utilizada uma planilha eletrônica Microsoft Excel. Para cada mês do período estudado fez-se um gráfico de dispersão utilizando os dados diários, correlacionou a temperatura do ar " $\mathrm{x}$ " com a temperatura do solo "y", feito de forma separada para cada profundidade do solo $(02$ e $20 \mathrm{~cm})$, obtendo assim dois gráficos para cada mês, um para camada de $02 \mathrm{~cm}$ e outro para de $20 \mathrm{~cm}$, para ambos anos estudado, 2011 e 2012, em seguida adicionou a linha de tendência do tipo linear e ativou as 

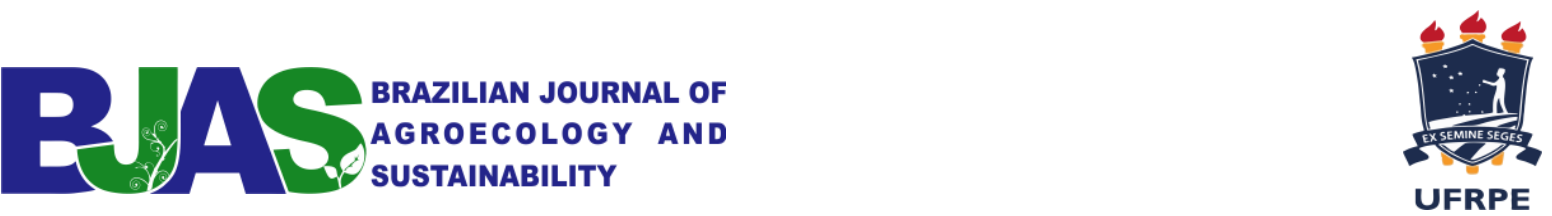

funções "Exibir equação no gráfico" e "Exibir o valor de R-quadrado no gráfico". Utilizou-se o coeficiente de correlação de Pearson "r" (Equação 1) para avaliar estatisticamente os métodos de estimativa da temperatura do solo em função da temperatura do ar. Esta metodologia quantifica a força de associação linear entre duas variáveis e, portanto, descreve quão bem uma linha reta se ajustaria através de uma nuvem de pontos de acordo com classificação proposta na Tabela 1.

$$
\mathrm{r}=\frac{\sum_{\mathrm{i}}(\mathrm{xi}-\overline{\mathrm{x}})(\mathrm{yi}-\overline{\mathrm{y}})}{\sqrt{\sum_{\mathrm{i}}(\mathrm{xi}-\overline{\mathrm{x}})^{2} \sum_{\mathrm{i}}(\mathrm{yi}-\overline{\mathrm{y}})^{2}}}
$$

$\mathrm{r}=$ coeficiente de correlação de Pearson, adimensional;

xi e yi = valores das variáveis $\mathrm{x}$ e y;

$\overline{\mathrm{y}}$ e $\overline{\mathrm{x}}=$ são respectivamente as médias dos valores $x i$ e $y i$

Tabela 1. Classificação dos valores do coeficiente de correlação de Pearson (r).

\begin{tabular}{c|c}
\hline $\begin{array}{c}\text { Coeficiente de } \\
\text { correlação }\end{array}$ & Classificação \\
\hline 0,0 a 0,1 & Muito baixa \\
0,1 a 0,3 & Baixa \\
0,3 a 0,5 & Moderada \\
0,5 a 0,7 & Alta \\
0,7 a 0,9 & Muito alta \\
0,9 a 1,0 & Quase perfeita \\
\hline
\end{tabular}

Fonte: Cunha et al. (20)

Todos parâmetros meteorológicos foram aferidas as médias mensais para cada ano separadamente e fez-se os gráficos para melhor visualização, todos em planilha eletrônica Microsoft Excel. Fez-se um gráfico da temperatura do solo de 02 e $20 \mathrm{~cm}$, temperatura do ar junto com a radiação global, para analisar a influência da mesma sob temperatura do ar e do solo. Foi feito um gráfico da precipitação pluviométrica junto com a da umidade relativa do ar. E um outro gráfico com dados médios mensais da velocidade do vento.

Foi feito uma tabela com todas variáveis médias mensais para avaliar a influência e o comportamento de cada variável relacionando com os dados estimados da equação da temperatura do solo. 


\section{RESULTADOS E DISCUSSÃO}

As Tabelas 2 e 3 apresentam os valores médios coletados ao longo do período avaliado (01/01/2011 a 31/12/2012), perfazendo um total de 17.520 dados para cada variável: temperatura do solo $\left(\mathrm{T}_{\mathrm{S}}\right)$ a 2 e a $20 \mathrm{~cm}$, temperatura do $\operatorname{ar}\left(\mathrm{T}_{\mathrm{ar}}\right)$, umidade relativa, precipitação pluviométrica, radiação global $\left(\mathrm{R}_{\mathrm{S}}\right)$ e velocidade do vento. $\mathrm{O}$ solo a $2 \mathrm{~cm}$ de profundidade apresentou temperaturas variando de 28,18 a $35,71{ }^{\circ} \mathrm{C}$ e a $20 \mathrm{~cm}$ de 28,27 a $35,15^{\circ} \mathrm{C}$. O valor médio para cada profundidade não variou muito, ficando em torno de $30,04{ }^{\circ} \mathrm{C}$ para o ano de 2011 e de $32,95{ }^{\circ} \mathrm{C}$ para no de 2012 . Ressalta-se, contudo, que o solo apresenta certa defasagem em relação à troca de calor, de acordo com Geiger (1980) o fluxo de calor no interior do solo é relativamente lento além do solo possuir grande capacidade de retenção de calor, sendo o tempo de variação da temperatura em função da variação da radiação solar de aproximadamente uma hora.

Tabela 2. Dados médio das variáveis avaliadas para cada mês do ano de 2011.

\begin{tabular}{|c|c|c|c|c|c|c|c|}
\hline Mês & $\begin{array}{l}\mathbf{T}_{\mathrm{ar}} \\
\left({ }^{\circ} \mathbf{C}\right)\end{array}$ & $\begin{array}{c}\text { Ts }_{\mathrm{s}} 2 \mathrm{~cm} \\
\left({ }^{\circ} \mathbf{C}\right)\end{array}$ & $\begin{array}{c}T_{\text {s }} 20 \mathrm{~cm} \\
\left({ }^{\circ} \mathrm{C}\right)\end{array}$ & $\begin{array}{c}\text { Rs } \\
\left(\mathrm{MJ} \mathrm{m}^{-2} \mathrm{dia}^{-}\right. \\
\left.\mathbf{1}^{-}\right)\end{array}$ & $\begin{array}{c}\text { Velocidade } \\
\text { do vento } \\
\left(\mathrm{m} \mathrm{s}^{-1}\right)\end{array}$ & $\begin{array}{c}\text { Umidade } \\
\text { do ar } \\
(\%)\end{array}$ & $\begin{array}{c}\text { Precipitação } \\
\text { total } \\
(\mathbf{m m})\end{array}$ \\
\hline Janeiro & 27,33 & 31,14 & 31,17 & 18,03 & 1,98 & 70,23 & 100,60 \\
\hline Fevereiro & 27,16 & 30,25 & 30,32 & 18,28 & 1,65 & 73,23 & 150,60 \\
\hline Março & 26,61 & 29,90 & 29,95 & 16,64 & 1,28 & 78,77 & 89,70 \\
\hline Abril & 26,09 & 29,52 & 29,64 & 15,01 & 1,07 & 81,89 & 237,00 \\
\hline Maio & 25,86 & 28,91 & 29,05 & 14,28 & 1,04 & 81,65 & 219,50 \\
\hline Junho & 25,87 & 28,60 & 28,76 & 14,04 & 1,17 & 74,52 & 18,60 \\
\hline Julho & 25,51 & 28,18 & 28,27 & 14,54 & 1,38 & 71,89 & 115,40 \\
\hline Agosto & 26,31 & 29,02 & 29,04 & 16,61 & 1,78 & 65,22 & 15,30 \\
\hline Setembro & 27,71 & 31,93 & 31,51 & 18,73 & 2,41 & 54,52 & 0,00 \\
\hline Outubro & 27,79 & 32,23 & 32,03 & 19,25 & 2,97 & 54,40 & 10,00 \\
\hline Novembro & 28,05 & 30,28 & 30,56 & 18,66 & 3,05 & 60,96 & 0,00 \\
\hline Dezembro & 28,05 & 30,53 & 30,50 & 17,90 & 3,08 & 61,75 & 0,00 \\
\hline Média & 26,86 & 30,04 & 30,07 & 16,83 & 1,91 & 69,09 & - \\
\hline Acumulado & & & & & & & 956,7 \\
\hline
\end{tabular}

As maiores médias de temperatura do solo foram verificadas entre os meses de setembro e dezembro para os dois anos, em especial nos meses de outubro com as maiores temperaturas de $32,23{ }^{\circ} \mathrm{C}$ (ano de 2011) e $35,71^{\circ} \mathrm{C}$ (ano de 2012), isto pode ser explicado devido às maiores intensidades de radiação solar registradas, que foram de 20,71 e 19,25 $\mathrm{MJ} \mathrm{m}^{-2} \mathrm{dia}^{-1}$, respectivamente. Segundo Carneiro et al. (2014), a temperatura do solo é uma função da disponibilidade de radiação solar na superfície do solo e das suas propriedades térmicas, com efeito significativo.

Tabela 3. Dados médio das variáveis avaliadas para cada mês do ano de 2012. 


\begin{tabular}{|c|c|c|c|c|c|c|c|}
\hline Mês & $\begin{array}{c}\mathbf{T}_{\text {ar }} \\
\left({ }^{\circ} \mathbf{C}\right)\end{array}$ & $\begin{array}{c}\text { Ts }_{\text {s }} 2 \mathbf{c m} \\
\left({ }^{\circ} \mathrm{C}\right)\end{array}$ & $\begin{array}{c}\mathbf{T}_{\mathbf{S}} 20 \mathrm{~cm} \\
\quad\left({ }^{\circ} \mathrm{C}\right)\end{array}$ & $\begin{array}{c}\mathbf{R s}_{\mathrm{S}} \\
\left(\mathbf{M J} \mathbf{m}^{-2}\right. \\
\left.\operatorname{dia}^{-1}\right)\end{array}$ & $\begin{array}{c}\text { Velocidade } \\
\text { do vento } \\
\left(\mathrm{m} \mathrm{s}^{-1}\right)\end{array}$ & $\begin{array}{c}\text { Umidade do } \\
\text { ar } \\
(\%)\end{array}$ & $\begin{array}{c}\text { Precipitação } \\
\text { total } \\
(\mathrm{mm})\end{array}$ \\
\hline Janeiro & 28,07 & 31,18 & 31,12 & 17,14 & 2,87 & 63,2 & 29,00 \\
\hline Fevereiro & 27,41 & 30,46 & 30,35 & 17,09 & 2,17 & 67,3 & 67,80 \\
\hline Março & 28,01 & 31,83 & 31,57 & 18,51 & 2,21 & 65,6 & 28,20 \\
\hline Abril & 28,23 & 31,36 & 31,39 & 17,87 & 2,14 & 63,8 & 33,00 \\
\hline Maio & 28,38 & 32,85 & 32,59 & 16,96 & 2,53 & 59,9 & 0,00 \\
\hline Junho & 27,78 & 31,46 & 31,55 & 15,47 & 2,29 & 60,4 & 26,90 \\
\hline Julho & 27,51 & 30,96 & 30,79 & 16,24 & 2,39 & 56,4 & 14,00 \\
\hline Agosto & 27,80 & 33,74 & 33,21 & 19,26 & 2,67 & 51,3 & 0,00 \\
\hline Setembro & 27,86 & 34,78 & 34,22 & 20,22 & 3,09 & 52,8 & 0,00 \\
\hline Outubro & 28,09 & 35,71 & 35,12 & 20,71 & 3,26 & 55,3 & 0,00 \\
\hline Novembro & 27,87 & 35,62 & 35,15 & 19,56 & 3,37 & 60,4 & 0,50 \\
\hline Dezembro & 28,40 & 35,51 & 34,98 & 18,81 & 3,27 & 60,3 & 0,00 \\
\hline Média & 27,95 & 32,95 & 32,67 & 18,15 & 2,69 & 59,72 & - \\
\hline Acumulado & & & & & & & 199,40 \\
\hline
\end{tabular}

Fonte: Tecla Ticiane

A radiação influencia as flutuações da temperatura do ar e da temperatura do solo ( $\mathrm{T}_{\mathrm{S}}$ ); consequentemente, o aumento da $\mathrm{T}_{\mathrm{S}}$ surge com o aumento da intensidade da radiação solar, sobre o mesmo. Isto pode ser observado nas Figuras 2 e 3. Os maiores índices de radiação ocorreram em setembro, outubro e novembro, período mais seco do ano. Carneiro et al. (2014) verificaram maiores taxas de temperatura do solo em torno de $32,6{ }^{\circ} \mathrm{C}$ e intensidades máximas de radiação solar $\left(28,5 \mathrm{~W} \mathrm{~m}^{-2}\right)$ no período seco.

Figura 2. Variação anual da radiação solar, temperatura do solo e do ar, no ano de 2011. 


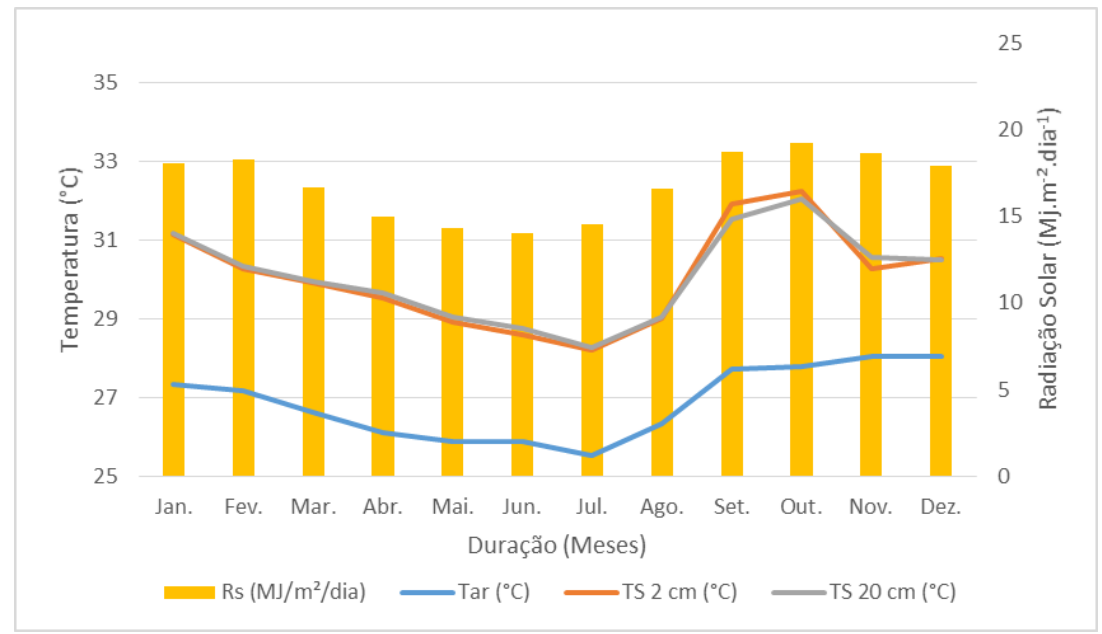

Fonte: Tecla Ticiane

Figura 3. Variação anual da radiação solar, temperatura do solo e do ar, no ano de 2012.

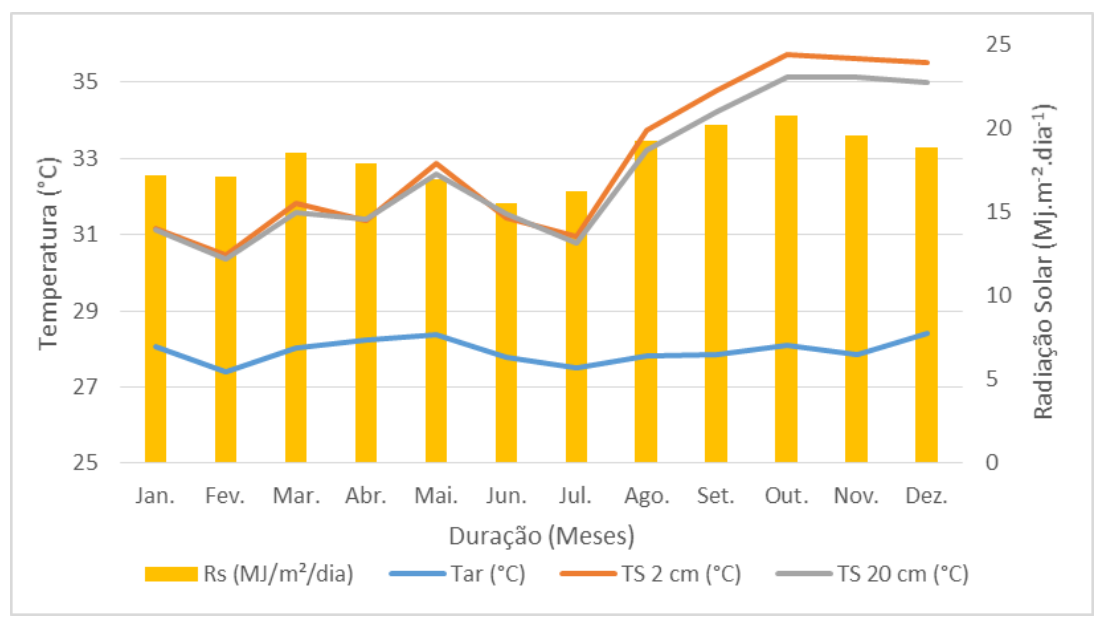

Fonte: Tecla Ticiane

Dentre o período estudado, a $T_{S}$ apresentou resposta imediata à intensidade da $R_{S}$, conforme supracitado anteriormente. Os menores valores de radiação solar foram verificados no mês de junho, sendo nos valores de 14,04 e 15,47 $\mathrm{MJ} \mathrm{m}^{-2}$ dia $^{-1}$ nos anos 2011 e 2012, respectivamente. Nos meses seguintes houve um crescimento da radiação solar até o mês de outubro, decrescendo nos meses de novembro e dezembro, o que contribuiu para que as linhas de temperatura do solo tivessem a mesma tendência ao longo do ano, pois quanto menor o nível de radiação disponível menor será o fluxo de energia para os níveis inferiores do solo. Gasparim, Ricieri, Silva, Dallacort, \& Gnoatto (2005) afirmam que é a partir da quantidade de radiação solar absorvida e perdida que a camada superficial do solo se aquece ou se resfria no 

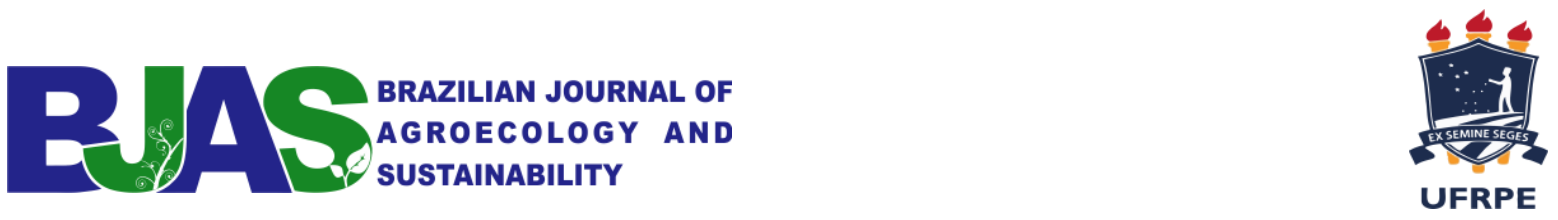

decorrer do dia e do ano, em resposta a tais fatores, gerando variações térmicas nas camadas mais próximas da superfície.

Além dos efeitos de insolação na temperatura do solo, outros efeitos semelhantes podem interferir na temperatura do ar. Santos, Araujo, Araujo, Rosa, \& Pazera (2009) afirmam que, quando ocorre maiores incidências da radiação solar e insolação, constata-se menor nebulosidade, como consequência tem-se uma relação inversa entre a umidade e a radiação solar global, que também pode ser verificado pela variabilidade temporal das condições meteorológicas.

Os maiores índices pluviométricos ocorreram em abril de 2011 e março de 2012, com acumulado de 237 e 67,8 mm, respectivamente (Tabelas 2 e 3; Figuras 4 e 5). Deste modo, observou-se uma tendência inversa entre precipitação pluviométrica e a temperatura do solo, com ocorrência de menores valores da $\mathrm{T}_{\mathrm{S}}$ sempre nos meses de maiores precipitações. $\mathrm{O}$ quadrimestre chuvoso na região normalmente vai de fevereiro a maio, porém na região semiárida esse comportamento pode sofrer modificações em alguns anos específicos, como foi o caso do ano de 2011, em que as precipitações se estenderam até julho, apresentando um total pluviométrico nesse período de $830,80 \mathrm{~mm}$, representando quase $90 \%$ da precipitação anual, com os menores valores da temperatura do ar e do solo a 2 e $20 \mathrm{~cm}$ ocorrendo entre maio e Julho; já no ano seco de 2012, a precipitação total foi de 169,90 mm nesse mesmo período, tendo menor $\mathrm{T}_{\mathrm{S}}$ no mês de Julho para ambas as profundidades.

Nas Tabelas 2 e 3; Figuras 4 e 5 pode-se observar a variação anual da precipitação pluviométrica e da umidade relativa do ar ao longo dos dois anos estudados. A umidade do ar no ano chuvoso apresentou maior amplitude variando de 54,40 a 81,89\% e, observou-se que em períodos de maiores valores de umidade menores foram os valores de temperatura do ar. Alves, Santos e Neves (2016) analisando a temperatura do ar na cidade de Iporá (GO), notaram que nos dias de ocorrência de precipitação houve aumento na umidade relativa do ar e diminuição na temperatura do ar, devido ao bloqueio da radiação solar global pelas nuvens e pelo processo de evapotranspiração intensificado pela precipitação.

Na Figura 4, que corresponde ao ano de 2011, ano chuvoso, verifica-se uma resposta da umidade relativa do ar com relação à precipitação pluviométrica, ou seja, os maiores valores de precipitação e umidade ocorreram no mês de abril, de $237 \mathrm{~mm}$ e $81,89 \%$, enquanto que os valores mais baixos de precipitação e umidade foram registrados de setembro a dezembro, sendo os valores de umidade mínimos registrados nos meses de setembro e outubro. Campos, Vieira, Back, \& Silva (2013) ao estudarem fluxos de radiação solar global em vinhedos de altitude de São Joaquim-SC verificaram maior incidência de radiação solar no período da 

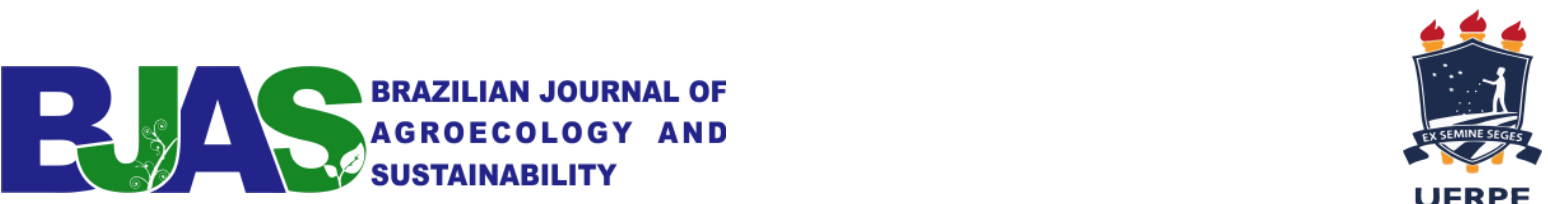

manhã, na comparação com o período da tarde, sugerindo portanto, que neste experimento, pode ter havido influência da nebulosidade, dada a ocorrência de precipitação pluvial no primeiro semestre do ano de 2011.

Figura 4. Umidade relativa do ar média e precipitação pluviométrica acumulada no ano de 2011.

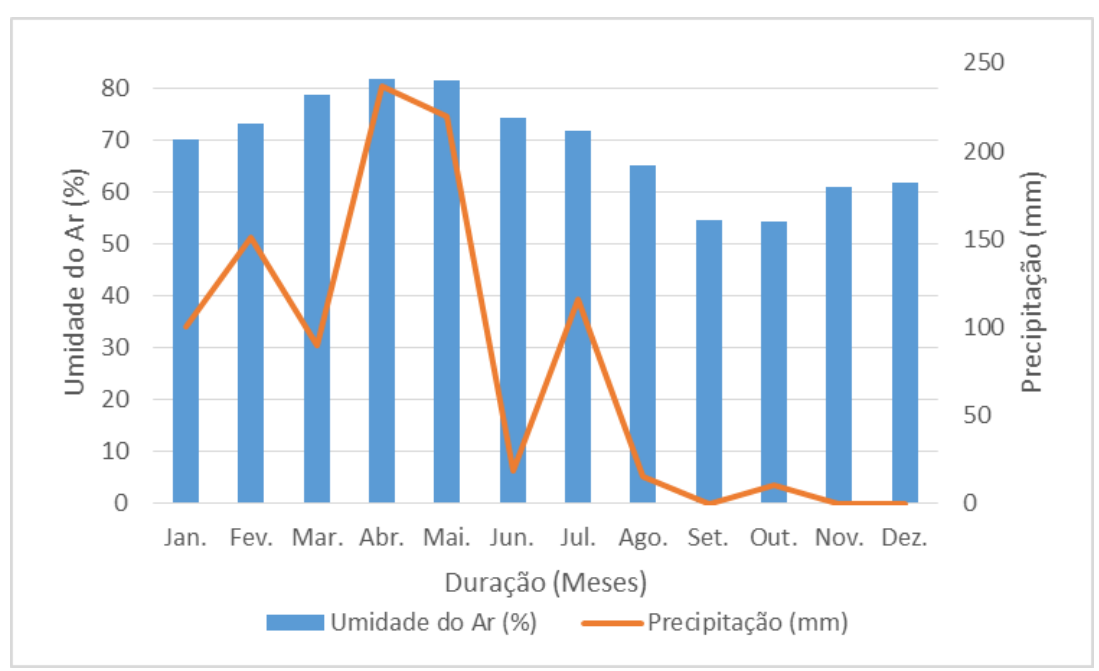

A Figura 5 apresenta a variação anual da precipitação pluviométrica e da umidade relativa do ar no ano seco de 2012. Verifica-se um comportamento anual da umidade semelhante ao ano chuvoso de 2011, porém com valores mais baixos, com os máximos próximos a 67\% enquanto que em 2011 os mesmos estiveram próximos a $82 \%$. A umidade mínima foi registrada em agosto, $50 \%$. A precipitação teve um comportamento bem diferente do ano anterior, com valor máximo em fevereiro próximo de $20 \mathrm{~mm}$ e valores zero de agosto a dezembro.

Figura 5. Umidade relativa do ar média e precipitação pluviométrica acumulada no ano de 2012 . 


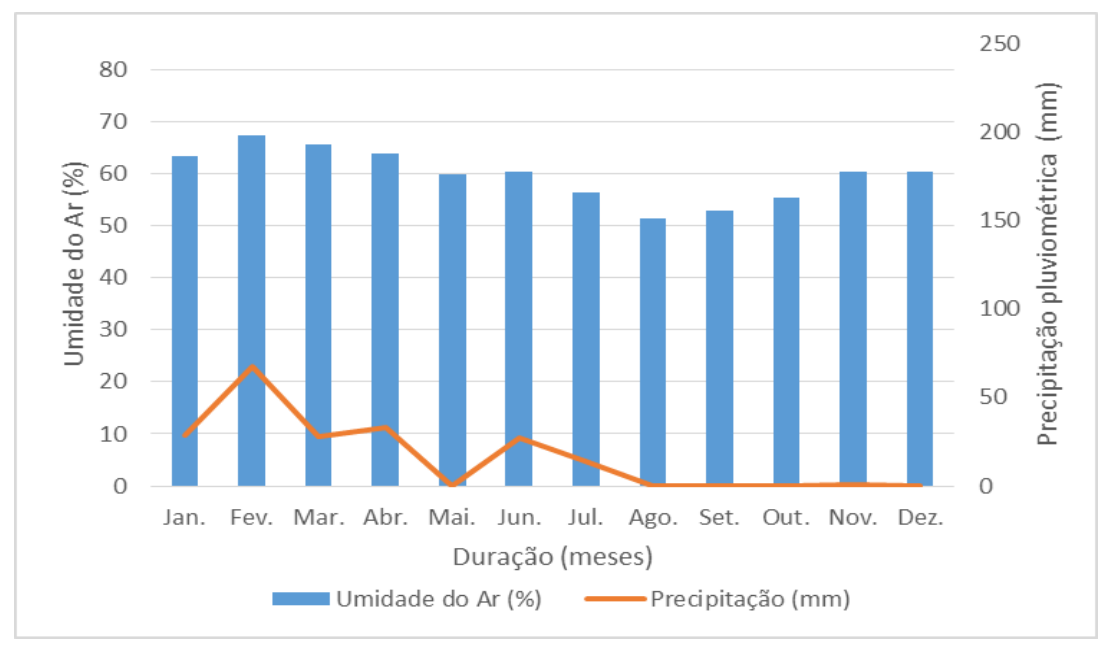

Os menores valores de umidade em setembro e outubro explica os maiores índices da radiação solar que foram registrados nesses meses. Segundo Carneiro et al. (2014), o regime pluviométrico exerce grande influência na incidência de radiação solar à superfície sendo, portanto, de grande contribuição para a variabilidade da TS no decorrer do ano. Quanto menor o índice de precipitação maior a intensidade da radiação solar e menor a umidade do ar.

A literatura, de um modo geral cita que existe uma estreita relação entre a radiação solar, a temperatura do ar e a velocidade do vento. Analisando-se as Figuras 4 e 5 e comparando-as com a variação da velocidade do vento ao longo do ano, notou-se um comportamento similar aos gráficos das Figuras 6 e 7. Quanto maior a $R_{S}$, maiores foram a velocidade do vento próximo a superfície e as temperaturas do ar e do solo. Pillar (1995) enfatiza que o aquecimento e resfriamento do ar é determinado pelo balanço de radiação da superfície do solo e da vegetação presente no local. As trocas de calor do ar com as superfícies se dão por condução e convecção, gerando movimentos turbulentos do ar (vento).

As Figuras 6 e 7 destacam uma tendência da velocidade do vento atingir seus valores máximos no segundo semestre do ano, enquanto que as menores velocidades são verificadas no primeiro semestre. Isso pode ser explicado pelo fato de que no segundo semestre os valores da temperatura são maiores e consequentemente os valores dos gradientes de pressão também serão maiores, influenciando na velocidade do vento. Já no primeiro semestre os valores são menores devido a ocorrência das chuvas e elevada nebulosidade e umidade do ar nesse período do ano.

Figura 6. Valores da velocidade do vento ao longo do ano de 2011. 


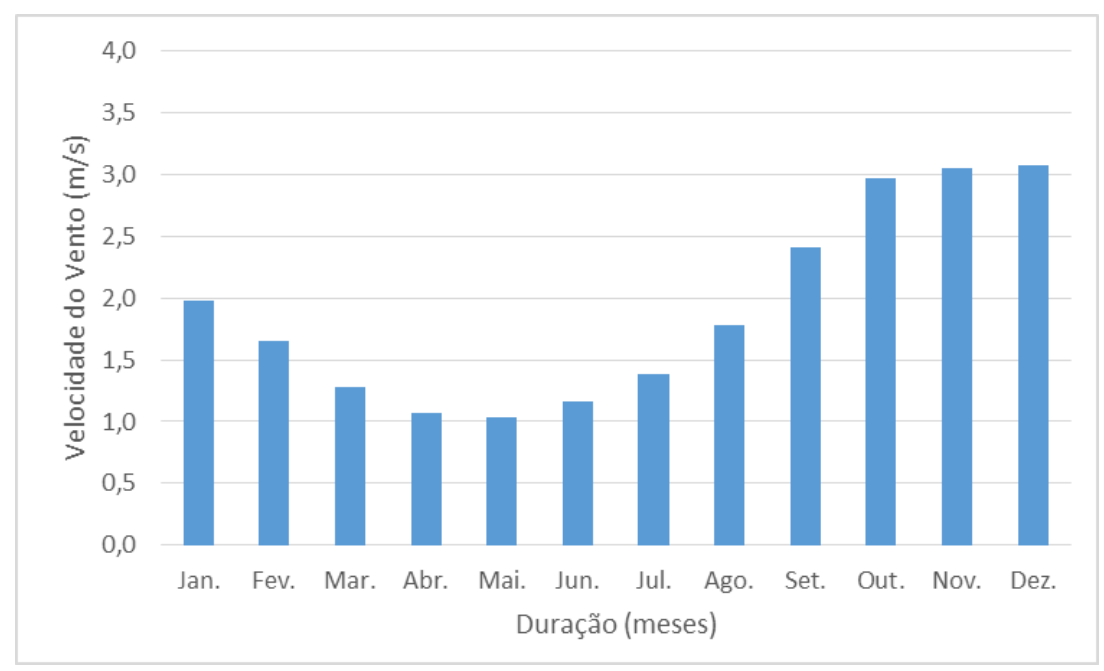

Então, a resposta do vento é inversamente proporcional a intensidades de chuvas e percentagem da umidade relativa do ar, quanto maior a precipitação e maior umidade no ambiente menor é a velocidade do vento, o mesmo aconteceu para o ano 2012. No ano chuvoso de 2011 a velocidade média do vento foi de $1,91 \mathrm{~m} \mathrm{~s}^{-1}$, sendo os valores extremos anuais de $1,04 \mathrm{~m} \mathrm{~s}^{-1}$ em maio e de 3,08 $\mathrm{m} \mathrm{s}^{-1}$ em dezembro. Alves e Biudes (2012) afirmam que a relação entre a vegetação e temperatura do ar ocorre no controle da radiação solar, do vento e da umidade do ar.

Figura 7. Valores da velocidade do vento ao longo do ano de 2012.

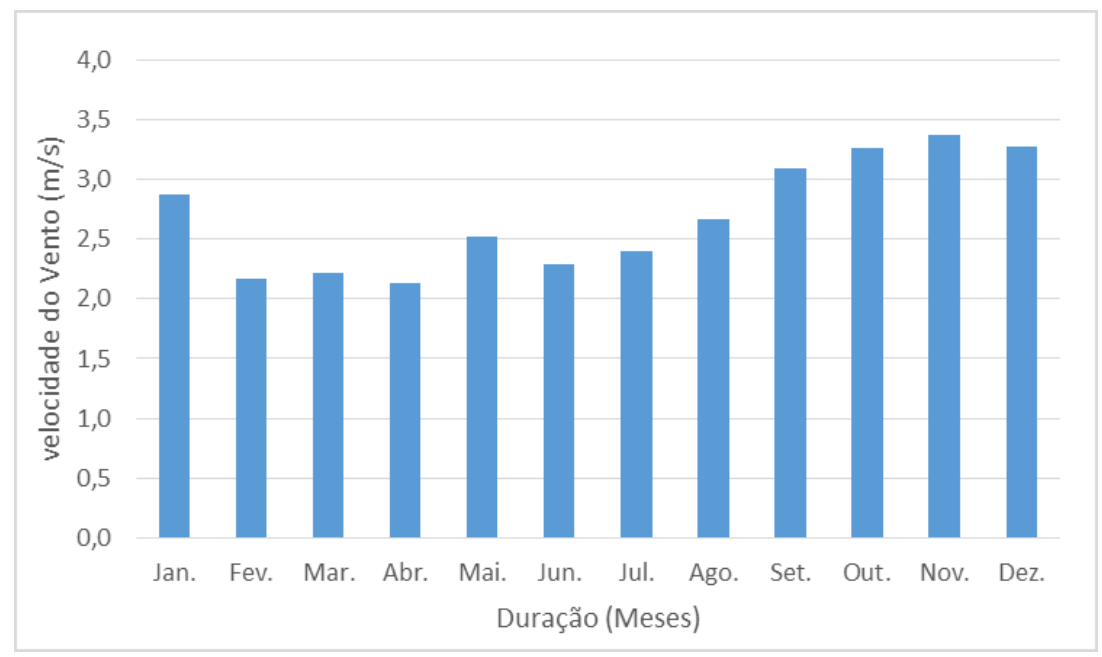

A Figura 7 apresenta a variação anual da velocidade do vento no ano seco de 2012. Percebe-se que neste ano os valores da velocidade do vento foram mais elevados, caracterizando ainda mais um ano de seca na região. A média anual foi de $2,69 \mathrm{~m} \mathrm{~s}^{-1}$, com valores extremos de $2,14 \mathrm{~m} \mathrm{~s}^{-1}$ em abril, e de $3,27 \mathrm{~m} \mathrm{~s}^{-1}$ em novembro e dezembro. Estes 

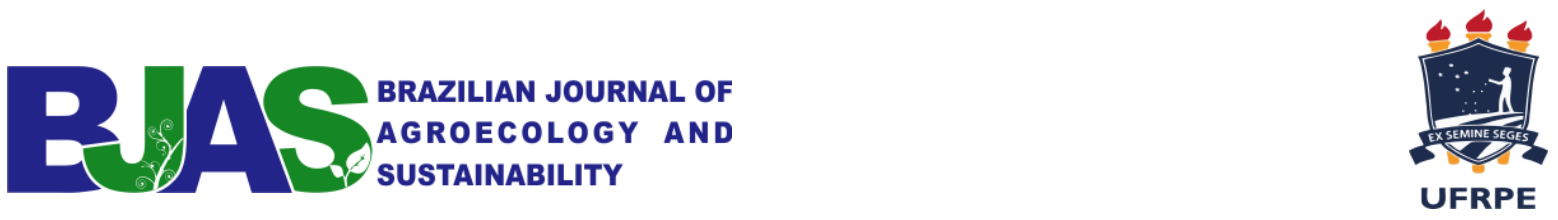

resultados foram influenciados pelas temperaturas do ar e do solo que registraram seus menores valores nos meses de menor velocidade do vento e maiores valores nos meses de maior velocidade do vento. Silva, Santos, Santos, \& White (2016) avaliando a temperatura do solo, temperatura do ar e umidade reativa do ar em uma clareira na Mata Atlântica afirmaram que o microclima é alterado devido às altas taxas de radiação solar que incidem nas bordas, intensificando a entrada de vento e elevando a temperatura do ar e do solo em áreas próximas.

Nesta secção, apresentam-se os resultados referentes a comparação entre os valores das temperaturas do solo estimadas nas profundidades de 2 e $20 \mathrm{~cm}$ para as duas condições climatológicas em um ano chuvoso (2011) e um ano seco (2012).

Os diagramas de dispersão apresentados nas Figuras 8 e 9 descrevem a variação da temperatura do solo $\left(\mathrm{T}_{\mathrm{S}}\right)$ em função da temperatura do $\operatorname{ar}\left(\mathrm{T}_{\mathrm{ar}}\right)$, nas profundidades de 2 e $20 \mathrm{~cm}$ para os anos de 2011 e 2012. Para o ano de 2011 o coeficiente estatístico de determinação $\left(\mathrm{R}^{2}\right)$ foi de 0,58 para $2 \mathrm{~cm}$, e de 0,56 para $20 \mathrm{~cm}$. Quando a análise é feita utilizando-se os coeficientes de correlação de Pearson (r), os índices de correlação apresentados resultaram em 0,76 para $2 \mathrm{~cm}$ e 0,74 para $20 \mathrm{~cm}$ para o ano chuvoso de 2011. Estes valores correspondem a uma correlação "muito alta" entre a temperatura do solo e do ar. Observa-se, ainda que à medida que aumenta a temperatura do ar, aumenta proporcionalmente a temperatura do solo. Belan, Xavier, Torres, Toledo, \& Pezzopane (2013) analisando a dinâmica entre temperatura do ar e do solo sob duas condições cobertas, concluíram que houve correlação positiva entre a temperatura do ar e a temperatura do solo nas condições de presença e ausência de cobertura vegetal morta.

Para o ano seco de 2012, o $\mathrm{R}^{2}$ encontrado para $2 \mathrm{~cm}$ de profundidade foi de 0,13 ; enquanto que para a profundidade a $20 \mathrm{~cm}$ foi de 0,09, como mostra a Figura 9. Analisando-se os pares de dados usando-se a metodologia da correlação de Pearson "r" para este ano foi classificado como "moderado" para as duas profundidades com valores de 0,36 a 0,31 para 2 e $20 \mathrm{~cm}$, respectivamente. Os valores das correlações deixam claro o baixo nível de concordância entre os dados da temperatura do ar e do solo para o ano de 2012. Essa relação não expressiva, indicada pelos menores valores de coeficientes de correlação indicam claramente uma certa desconfiança para o uso dessa metodologia para anos considerados secos na região de Mossoró.

Figura 8. Correlação entre a temperatura do ar e a temperatura do solo nas profundidades de 2 cm (a) e $20 \mathrm{~cm}$ (b) para o ano de 2011. 

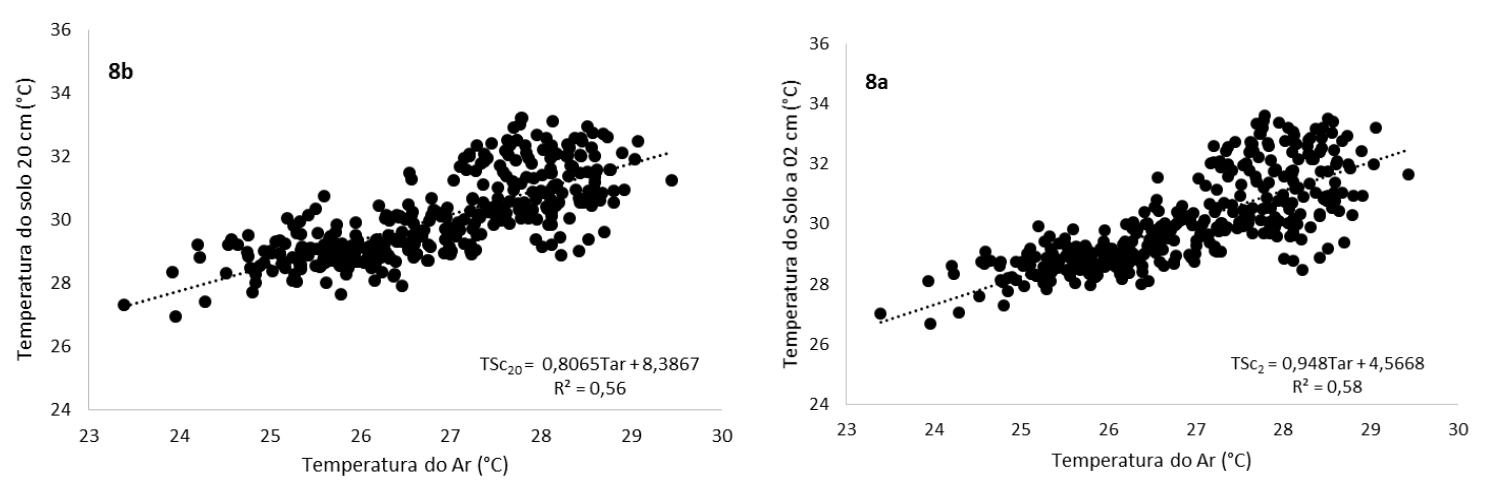

Figura 9. Correlação entre a temperatura do ar e a temperatura do solo nas profundidades de 2 cm (a) e $20 \mathrm{~cm}$ (b) para o ano de 2012.
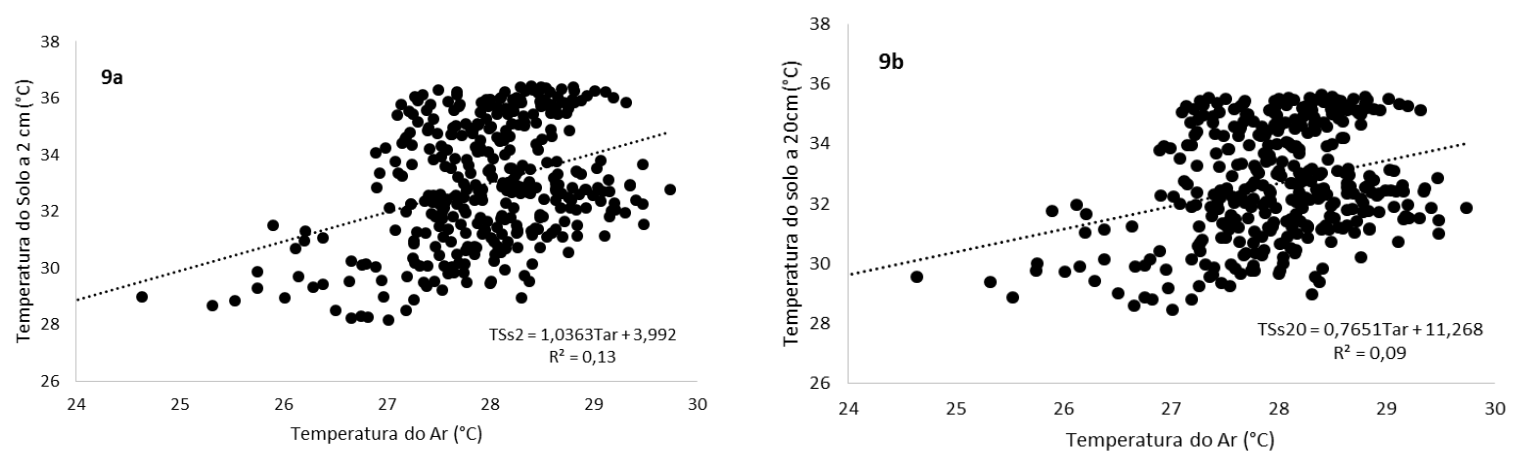

Nota-se que quanto maior a profundidade do solo, há um decréscimo na correlação entre temperatura do solo e do ar, evidenciando assim, o efeito desse fator no comportamento das variáveis. Corroborando com os resultados do presente estudo, Belan et al. (2013) observaram que a medida que aumenta a temperatura do ar aumenta proporcionalmente a temperatura do solo, no entanto essa relação vai se reduzindo gradativamente ao longo do perfil.

Pelos coeficientes de determinação, pode-se observar que as equações lineares obtidas se ajustaram no ano chuvoso para ambas as profundidades estudadas, porém no período seco o coeficiente de determinação foi muito baixo.

Usando-se a metodologia de Pearson, foram analisados os comportamentos da temperatura do solo e do ar para cada mês e obteve-se a equação estimada para 2 e $20 \mathrm{~cm}$ para os dois anos estudados. No ano de 2011 para $2 \mathrm{~cm}$ de profundidade, os coeficientes de correlação apresentaram correlação desde "quase perfeita" a "baixa" mostrando-se melhor para os primeiros meses do ano (Tabela 4). 

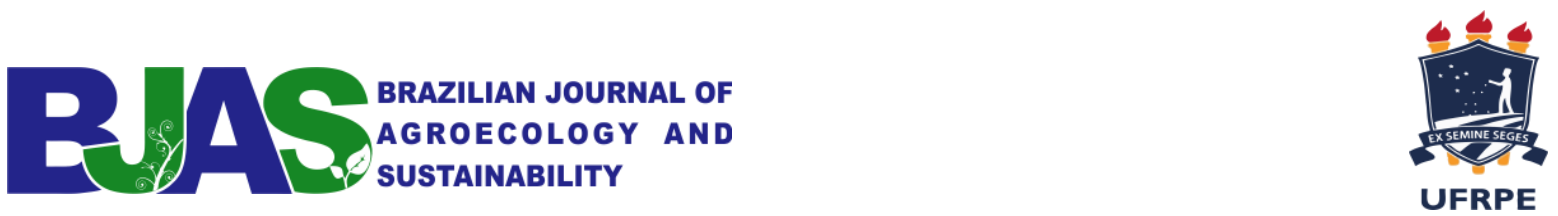

As melhores correlações obtidas foram para o período chuvoso, em especial para o mês de março com correlação quase perfeita, sendo assim, a equação se ajusta para esse período em um ano chuvoso com o índice de determinação $\left(\mathrm{R}^{2}\right)$ de 0,87 e " $\mathrm{r}$ " de 0,93 , porém mesmo apresentando reposta positiva da equação, em períodos secos a equação pode não ter um bom ajuste, como é o caso do mês de outubro.

Tabela 4. Média da temperatura do solo a $2 \mathrm{~cm}$ e do ar diária para os meses de 2011 e respectivas equações de estimativa para a temperatura do solo, correlação e classificação.

\begin{tabular}{|c|c|c|c|c|c|c|}
\hline Mês & $\begin{array}{l}\mathbf{T}_{\text {ar }} \\
\left({ }^{\circ} \mathbf{C}\right)\end{array}$ & $\begin{array}{c}\mathbf{T}_{\mathrm{Sc}} \mathbf{2} \\
\mathbf{c m} \\
\left({ }^{\circ} \mathbf{C}\right)\end{array}$ & Equação & $\mathbf{R}^{2}$ & $\mathbf{r}$ & Classificação \\
\hline Janeiro & 27,33 & 31,14 & $\mathrm{~T}_{\mathrm{Sc}} 2=0,8308 \mathrm{~T}_{\mathrm{ar}}+8,4389$ & $\mathrm{R}^{2}=0,62$ & 0,83 & Muito alta \\
\hline Fevereiro & 27,16 & 30,25 & $\mathrm{~T}_{\mathrm{Sc}} 2=0,7631 \mathrm{~T}_{\mathrm{ar}}+9,5306$ & $\mathrm{R}^{2}=0,73$ & 0,85 & Muito alta \\
\hline Março & 26,61 & 29,90 & $\mathrm{~T}_{\mathrm{Sc}} 2=0,6084 \mathrm{~T}_{\mathrm{ar}}+13,714$ & $\mathbf{R}^{2}=\mathbf{0 , 8 7}$ & $\mathbf{0 , 9 3}$ & Quase perfeita \\
\hline Abril & 26,09 & 29,52 & $\mathrm{~T}_{\mathrm{Sc}} 2=0,4643 \mathrm{~T}_{\mathrm{ar}}+17,401$ & $\mathrm{R}^{2}=0,61$ & 0,78 & Muito alta \\
\hline Maio & 25,86 & 28,91 & $\mathrm{~T}_{\mathrm{Sc}} 2=0,5262 \mathrm{~T}_{\mathrm{ar}}+15,304$ & $\mathrm{R}^{2}=0,53$ & 0,73 & Muito alta \\
\hline Junho & 25,87 & 28,60 & $\mathrm{~T}_{\mathrm{Sc}} 2=0,3688 \mathrm{~T}_{\mathrm{ar}}+19,057$ & $\mathrm{R}^{2}=0,57$ & 0,76 & Muito alta \\
\hline Julho & 25,51 & 28,18 & $\mathrm{~T}_{\mathrm{Sc}} 2=0,48 \mathrm{~T}_{\mathrm{ar}}+15,911$ & $\mathrm{R}^{2}=0,53$ & 0,73 & Muito alta \\
\hline Agosto & 26,31 & 29,02 & $\mathrm{~T}_{\mathrm{Sc}} 2=0,3824 \mathrm{~T}_{\mathrm{ar}}+18,96$ & $\mathrm{R}^{2}=0,42$ & 0,64 & Alta \\
\hline Setembro & 27,71 & 31,93 & $\mathrm{~T}_{\mathrm{Sc}} 2=0,515 \mathrm{~T}_{\mathrm{ar}}+17,656$ & $\mathrm{R}^{2}=0,14$ & 0,37 & Moderada \\
\hline Outubro & 27,79 & 32,23 & $\mathrm{~T}_{\mathrm{Sc}} 2=0,7453 \mathrm{~T}_{\mathrm{ar}}+11,544$ & $R^{2}=\mathbf{0 , 0 8}$ & 0,28 & Baixa \\
\hline Novembro & 28,05 & 30,28 & $\mathrm{~T}_{\mathrm{Sc}} 2=0,4926 \mathrm{~T}_{\mathrm{ar}}+16,459$ & $\mathrm{R}^{2}=0,16$ & 0,40 & Moderada \\
\hline Dezembro & 28,05 & 30,53 & $\mathrm{~T}_{\mathrm{Sc}} 2=0,903 \mathrm{~T}_{\mathrm{ar}}+5,1971$ & $\mathrm{R}^{2}=0,13$ & 0,36 & Moderada \\
\hline Média & 26,86 & 30,04 & - & $\mathrm{R}^{2}=0,45$ & - & - \\
\hline
\end{tabular}

Nos diagramas de dispersão, Figura 10, observa-se melhor o comportamento para os dois valores extremos, os pontos e as linhas ficaram bem alinhados para o mês de março, enquanto o mês de outubro, que foi considerado o mais baixo índice de determinação ficou disperso.

Figura 10. Diagrama de dispersão para a temperatura do solo a $2 \mathrm{~cm}$ de profundidade em função da temperatura do ar, correspondente ao período de março (a) e outubro (b) do ano de 2011.
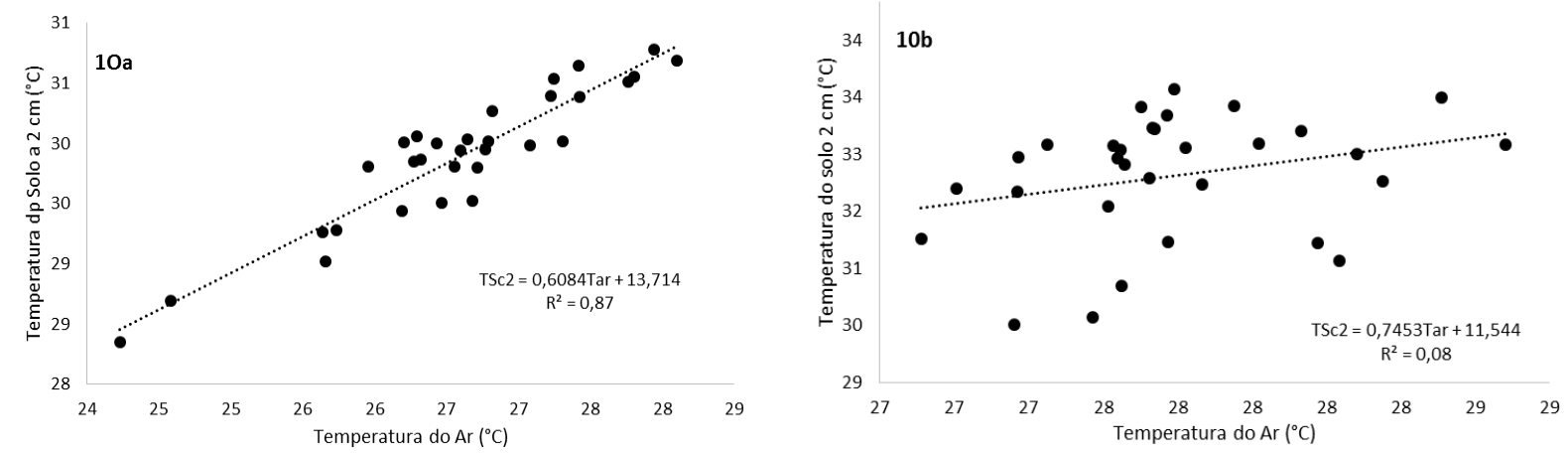


\section{RAS \\ AGROECOLOGY AND \\ SUSTAINABILITY}

Fonte: Tecla Ticiane

A mesma análise foi realizada para a profundidade de $20 \mathrm{~cm}$, Tabela 5 . Os resultados foram similares aos de $2 \mathrm{~cm}$ de profundidade. A equação mais representativa foi no mês de março com a maior correlação, 0,79 e coeficiente de determinação de 0,62 e classificação "muito alta". A pior classificação ficou para o mês de novembro, "baixa", com $\mathrm{R}^{2}$ de 0,02 e "r" de 0,16 . O coeficiente de determinação médio para o ano foi 0,2827 . O fato que pode explicar o porque da correlação tão baixa para os meses de secos, pode estar associado à maior incidência de radiação solar, maiores velocidades do vento e maior temperatura do solo e do ar, ou seja, o modelo estudado não se ajustou bem para a profundidade de $20 \mathrm{~cm}$ nas situações climáticas normalmente ocorridas no segundo semestre na região.

Tabela 5. Média da temperatura do solo a $20 \mathrm{~cm}$ e do ar diária para os meses de $2011 \mathrm{e}$ respectivas equações de estimativa da temperatura do solo, correlação e classificação.

\begin{tabular}{ccccccc}
\hline Mês & $\begin{array}{c}\mathbf{T}_{\text {ar }} \\
\left({ }^{\circ} \mathbf{C}\right)\end{array}$ & $\begin{array}{c}\mathbf{T}_{\mathbf{S c}} \mathbf{2 0} \mathbf{~ c m} \\
\left({ }^{\circ} \mathbf{C}\right)\end{array}$ & Equação & $\mathbf{R}^{\mathbf{2}}$ & $\mathbf{r}$ & Classificação \\
\hline Janeiro & 27,33 & 31,17 & $\mathrm{~T}_{\mathrm{Sc} 20=0,5278 \mathrm{~T}_{\mathrm{ar}}+16,749}$ & $\mathrm{R}^{2}=0,41$ & 0,76 & Muito alta \\
Fevereiro & 27,16 & 30,32 & $\mathrm{~T}_{\mathrm{Sc} 20}=0,5375 \mathrm{~T}_{\mathrm{ar}}+15,725$ & $\mathrm{R}^{2}=0,57$ & 0,76 & Muito alta \\
Março & 26,61 & 29,95 & $\mathrm{~T}_{\mathrm{Sc} 20=0,4023 \mathrm{~T}_{\mathrm{ar}}+19,246}$ & $\mathbf{R}^{2}=\mathbf{0 , 6 2}$ & $\mathbf{0 , 7 9}$ & Muito alta \\
Abril & 26,09 & 29,64 & $\mathrm{~T}_{\mathrm{Sc} 20}=0,3182 \mathrm{~T}_{\mathrm{ar}}+21,334$ & $\mathrm{R}^{2}=0,41$ & 0,64 & Alta \\
Maio & 25,86 & 29,05 & $\mathrm{~T}_{\mathrm{Sc} 20}=0,2466 \mathrm{~T}_{\mathrm{ar}}+22,676$ & $\mathrm{R}^{2}=0,26$ & 0,51 & Alta \\
Junho & 25,87 & 28,76 & $\mathrm{~T}_{\mathrm{Sc} 20}=0,1509 \mathrm{~T}_{\mathrm{ar}}+24,859$ & $\mathrm{R}^{2}=0,26$ & 0,51 & Alta \\
Julho & 25,51 & 28,27 & $\mathrm{~T}_{\mathrm{Sc} 20}=0,3532 \mathrm{~T}_{\mathrm{ar}}+19,257$ & $\mathrm{R}^{2}=0,36$ & 0,60 & Alta \\
Agosto & 26,31 & 29,04 & $\mathrm{~T}_{\mathrm{Sc} 20=0,1901 \mathrm{~T}_{\mathrm{ar}}+24,041}$ & $\mathrm{R}^{2}=0,19$ & 0,44 & Moderada \\
Setembro & 27,71 & 31,51 & $\mathrm{~T}_{\mathrm{Sc} 20}=0,4769 \mathrm{~T}_{\mathrm{ar}}+18,298$ & $\mathrm{R}^{2}=0,14$ & 0,37 & Moderada \\
Outubbro & 27,79 & 32,03 & $\mathrm{~T}_{\mathrm{Sc} 20=0,447 \mathrm{~T}_{\mathrm{ar}}+19,609}$ & $\mathrm{R}^{2}=0,05$ & 0,21 & Baixa \\
Novembro & 28,05 & 30,56 & $\mathrm{~T}_{\mathrm{Sc} 20=0,1816 \mathrm{~T}_{\mathrm{ar}}+25,466}$ & $\mathbf{R}^{2}=\mathbf{0 , 0 2}$ & $\mathbf{0 , 1 6}$ & Baixa \\
Dezembro & 28,05 & 30,50 & $\mathrm{~T}_{\mathrm{Sc} 20=0,6464 \mathrm{~T}_{\mathrm{ar}}+12,367}$ & $\mathrm{R}^{2}=0,10$ & 0,32 & Baixa \\
\hline Média & 26,86 & 30,07 & - & $\mathrm{R}^{2}=0,28$ & - & - \\
\hline
\end{tabular}

As mesmas análises foram feitas para o ano seco de 2012. Os resultados estão apresentados na Tabela 6 e foram bastante diferentes dos apresentados no ano chuvoso de 2011 . Destaca-se os meses de fevereiro com melhor indice de determinação $\left(R^{2}=0,68\right)$ e classificação segundo Pearson de "muito alta" $(\mathrm{r}=0,82)$. Contrastando com fevereiro, verificou-se o mês de setembro com $\mathrm{R}^{2}$ de 0,02 , e "r" de 0,14 , classificação segundo Pearson "baixa". O coeficiente de determinação médio para $2 \mathrm{~cm}$ em 2012 foi 0,32, coeficiente muito baixo para se recomendar o modelo estudado. 
Tabela 6. Média da temperatura do solo a $2 \mathrm{~cm}$ e do ar diária para os meses de 2012 e respectivas equações estimada da temperatura do solo, correlação e classificação.

\begin{tabular}{ccccccc}
\hline Mês & $\begin{array}{c}\mathbf{T}_{\text {ar }} \\
\left({ }^{\circ} \mathbf{C}\right)\end{array}$ & $\begin{array}{c}\mathbf{T}_{\mathrm{Ss}} \mathbf{2} \mathbf{~ c m} \\
\left({ }^{\mathbf{0}} \mathbf{C}\right)\end{array}$ & $\mathbf{E q u a c ̧ a ̃ o}$ & $\mathbf{R}^{\mathbf{2}}$ & $\mathbf{r}$ & Classificação \\
\hline Janeiro & 28,07 & 31,18 & $\mathrm{~T}_{\mathrm{Ss}} 2=1,1084 \mathrm{~T}_{\mathrm{ar}}+0,0308$ & $\mathrm{R}^{2}=0,40$ & 0,63 & Alta \\
Fevereiro & 27,41 & 30,46 & $\mathrm{~T}_{\mathrm{Ss}} 2=0,6942 \mathrm{~T}_{\mathrm{ar}}+11,438$ & $\mathbf{R}^{2}=\mathbf{0 , 6 8}$ & $\mathbf{0 , 8 2}$ & Muito alta \\
Março & 28,01 & 31,83 & $\mathrm{~T}_{\mathrm{Ss}} 2=0,5278 \mathrm{~T}_{\mathrm{ar}}+17,041$ & $\mathrm{R}^{2}=0,21$ & 0,46 & Moderada \\
Abril & 28,23 & 31,36 & $\mathrm{~T}_{\mathrm{Ss}} 2=0,7789 \mathrm{~T}_{\mathrm{ar}}+9,3729$ & $\mathrm{R}^{2}=0,49$ & 0,70 & Muito alta \\
Maio & 28,38 & 32,85 & $\mathrm{~T}_{\mathrm{ss}} 2=0,3285 \mathrm{~T}_{\mathrm{ar}}+23,528$ & $\mathrm{R}^{2}=0,23$ & 0,47 & Moderada \\
Junho & 27,78 & 31,46 & $\mathrm{~T}_{\mathrm{S} s} 2=1,6153 \mathrm{~T}_{\mathrm{ar}}-13,42$ & $\mathrm{R}^{2}=0,54$ & 0,74 & Muito alta \\
Julho & 23,67 & 26,68 & $\mathrm{TSSs}_{2} 2=0,53444 \mathrm{~T}_{\mathrm{ar}}+16,303$ & $\mathrm{R}^{2}=0,07$ & 0,27 & Baixa \\
Agosto & 27,80 & 33,74 & $\mathrm{~T}_{\mathrm{Ss}} 2=0,1562 \mathrm{~T}_{\mathrm{ar}}+29,394$ & $\mathrm{R}^{2}=0,03$ & 0,17 & Baixa \\
Setembro & 27,86 & 34,78 & $\mathrm{~T}_{\mathrm{Ss}} 2=0,1565 \mathrm{~T}_{\mathrm{ar}}+30,423$ & $\mathbf{R}^{2}=\mathbf{0 , 0 2}$ & $\mathbf{0 , 1 4}$ & Baixa \\
Outubro & 28,09 & 35,71 & $\mathrm{~T}_{\mathrm{Ss}} 2=0,3602 \mathrm{~T}_{\mathrm{ar}}+25,611$ & $\mathrm{R}^{2}=0,12$ & 0,35 & Moderada \\
Novembro & 27,87 & 35,62 & $\mathrm{~T}_{\mathrm{Ss}} 2=0,7046 \mathrm{~T}_{\mathrm{ar}}+15,982$ & $\mathrm{R}^{2}=0,34$ & 0,59 & Moderada \\
Dezembro & 28,40 & 35,51 & $\mathrm{~T}_{\mathrm{Ss}} 2=0,83644 \mathrm{~T}_{\mathrm{ar}}+11,757$ & $\mathrm{R}^{2}=0,44$ & 0,66 & Alta \\
\hline Média & 27,63 & 32,60 & - & $\mathrm{R}^{2}=0,32$ & - & - \\
\hline
\end{tabular}

As Figuras 11a e 11b apresentam os gráficos de dispersão, para os dois meses extremos já discutidos. No mês de fevereiro a correlação foi melhor, provavelmente por ter sido um mês com a presença de chuvas, corroborando com os resultados encontrados no primeiro semestre chuvoso de 2011. Já o mês de setembro destaca-se negativamente com a pior estimativa dos dois anos estudados. Percebe-se um grande espalhamento dos pares de dados em torno da linha de tendência. A baixa correlação encontrada desaprova totalmente o modelo para uso neste mês.

Figura 11. Diagramas de dispersão para a temperatura do solo a $2 \mathrm{~cm}$ de profundidade em função da temperatura do ar, correspondente ao período de fevereiro (11) e setembro (11) do ano de 2012.
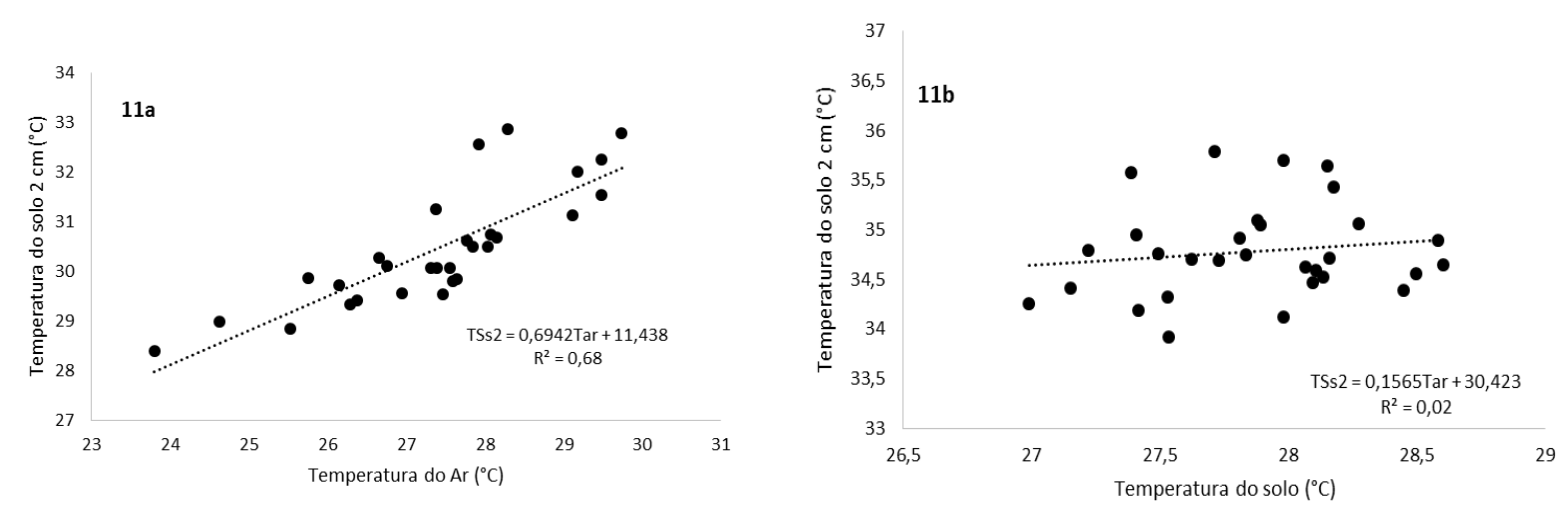

Fonte: Tecla Ticiane

Para a pronfundade de $20 \mathrm{~cm}$, Tabela 7, os resultados não foram muito diferentes de 2 cm, como pode-se observar pelo valor médio anual do coeficiente de determinação no valor de 0,16 . O mês de fevereiro apresentou-se como o menos ruim com $\mathrm{R}^{2}$ de 0,52 ; e " $\mathrm{r}$ " de 0,72 e 

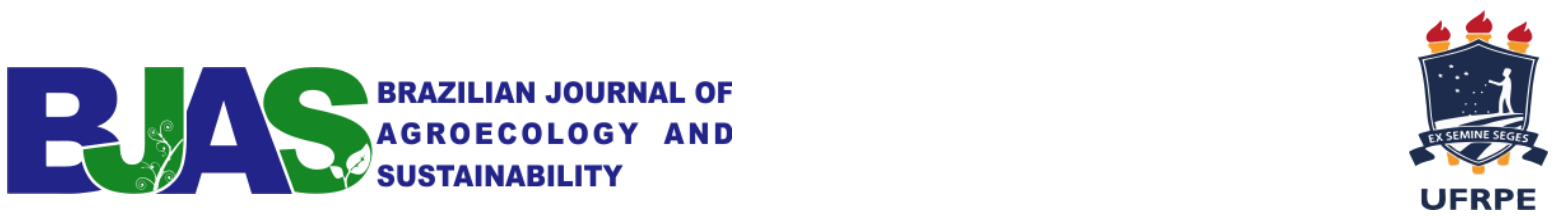

classificação segundo Pearson foi "alta". O mês de setembro, mais uma vez destacou-se como o pior, com com $\mathrm{R}^{2}$ de 0,01 , e "r" de 0,05 e classificação segundo Pearson foi "Muito baixa". A explicação para o fraco desempenho do método para $20 \mathrm{~cm}$ de profundidade pode estar associada ao fato de que as trocas de energia entre a atmosfera e o solo ficam mascaradas em condições de seca e à medida em que se aprofunda no solo. Sugere-se que futuramente sejam desenvolvidos outros trabalhos específicos a fim de estudar essa relação atmosfera-solo. Só assim pode-se obter uma resposta mais confiável.

Tabela 7. Média da temperatura do solo a $20 \mathrm{~cm}$ e do ar diária para os meses de 2012 e respectivas equações estimada da temperatura do solo, correlação e classificação.

\begin{tabular}{|c|c|c|c|c|c|c|}
\hline Mês & $\begin{array}{l}\mathbf{T}_{\mathrm{ar}} \\
\left({ }^{\circ} \mathbf{C}\right)\end{array}$ & $\begin{array}{c}\mathrm{T}_{\mathrm{Ss}} 20 \mathrm{~cm} \\
\left({ }^{\circ} \mathrm{C}\right)\end{array}$ & Equação & $\mathbf{R}^{2}$ & $\mathbf{r}$ & Classificação \\
\hline Janeiro & 28,07 & 31,12 & $\mathrm{~T}_{\mathrm{Ss} 20}=0,7415 \mathrm{~T}_{\mathrm{ar}}+10,269$ & $\mathrm{R}^{2}=0,27$ & 0,52 & Moderada \\
\hline Fevereiro & 27,41 & 30,35 & $\mathrm{~T}_{\mathrm{Ss} 20}=0,4651 \mathrm{~T}_{\mathrm{ar}}+17,61$ & $R^{2}=\mathbf{0 , 5 2}$ & $\mathbf{0 , 7 2}$ & Alta \\
\hline Março & 28,01 & 31,57 & $\mathrm{~T}_{\mathrm{ss} 20}=0,2191 \mathrm{~T}_{\mathrm{ar}}+25,428$ & $\mathrm{R}^{2}=0,07$ & 0,26 & Baixa \\
\hline Abril & 28,23 & 31,39 & $\mathrm{~T}_{\mathrm{ss} 20}=0,1775 \mathrm{~T}_{\mathrm{ar}}+26,372$ & $\mathrm{R}^{2}=0,05$ & 0,23 & Baixa \\
\hline Maio & 28,38 & 32,59 & $\mathrm{~T}_{\mathrm{ss} 20}=0,0953 \mathrm{~T}_{\mathrm{ar}}+29,881$ & $\mathrm{R}^{2}=0,04$ & 0,20 & Baixa \\
\hline Junho & 27,78 & 31,55 & $\mathrm{~T}_{\mathrm{Ss}} 20=1,2571 \mathrm{~T}_{\mathrm{ar}}-3,4588$ & $\mathrm{R}^{2}=0,48$ & 0,69 & Alta \\
\hline Julho & 23,67 & 26,69 & $\mathrm{~T}_{\mathrm{Ss} 2} 2=0,2456 \mathrm{~T}_{\mathrm{ar}}+24,035$ & $\mathrm{R}^{2}=0,02$ & 0,15 & Baixa \\
\hline Agosto & 27,80 & 33,21 & $\mathrm{~T}_{\mathrm{Ss} 20}=0,1091 \mathrm{~T}_{\mathrm{ar}}+30,175$ & $\mathrm{R}^{2}=0,02$ & 0,13 & Baixa \\
\hline Setembro & 27,86 & 34,22 & $\mathrm{~T}_{\mathrm{Ss} 20}=0,0453 \mathrm{~T}_{\mathrm{ar}}+32,955$ & $\mathbf{R}^{2}=\mathbf{0 , 0 1}$ & 0,05 & Muito baixa \\
\hline Outubro & 28,09 & 35,12 & $\mathrm{~T}_{\mathrm{Ss} 20}=0,1503 \mathrm{~T}_{\mathrm{ar}}+30,903$ & $\mathrm{R}^{2}=0,05$ & 0,23 & Baixa \\
\hline Novembro & 27,87 & 35,15 & $\mathrm{~T}_{\mathrm{Ss}} 20=0,3184 \mathrm{~T}_{\mathrm{ar}}+26,272$ & $\mathrm{R}^{2}=0,21$ & 0,46 & Moderada \\
\hline Dezembro & 28,40 & 34,98 & $\mathrm{~T}_{\mathrm{Ss}} 20=0,258 \mathrm{~T}_{\mathrm{ar}}+27,65$ & $\mathrm{R}^{2}=0,19$ & 0,60 & Alta \\
\hline Média & 27,63 & 32,33 & - & $\mathrm{R}^{2}=0,16$ & - & - \\
\hline
\end{tabular}

Finalmente, verificou-se uma pequena variação da temperatura do ar e do solo entre os anos chuvoso de 2011 e o ano seco de 2012. O ano chuvoso registrou temperaturas médias do ar de $26,86{ }^{\circ} \mathrm{C}$ com mínima de $25,51^{\circ} \mathrm{C}$ e máxima de $28,05^{\circ} \mathrm{C}$. Em 2012 esses valores foram em média de $27,63{ }^{\circ} \mathrm{C}$; mínima de $23,67{ }^{\circ} \mathrm{C}$ e máxima de $28,40{ }^{\circ} \mathrm{C}$. Para profundidade a $2 \mathrm{~cm}$ em 2011 os valores foram: média $30,04{ }^{\circ} \mathrm{C}$, mínima $28,18{ }^{\circ} \mathrm{C}$ e máxima $30,25{ }^{\circ} \mathrm{C}$. Em 2012 foram registrados média de $32,60{ }^{\circ} \mathrm{C}$, mínima de $30,46{ }^{\circ} \mathrm{C}$ e máxima de $35,71{ }^{\circ} \mathrm{C}$. Para a profundidade de $20 \mathrm{~cm}$ em 2011 a média foi de $30,07{ }^{\circ} \mathrm{C}$, mínima de $28,27{ }^{\circ} \mathrm{C}$ e máxima de $31,17{ }^{\circ} \mathrm{C}$. Em 2012 foram registradas média de $32,33{ }^{\circ} \mathrm{C}$, mínima de $30,35{ }^{\circ} \mathrm{C}$ e máxima de $35,15^{\circ} \mathrm{C}$. As temperaturas a $2 \mathrm{~cm}$ de profundidade apresentaram-se sempre maiores que a de $20 \mathrm{~cm}$, principalmente no segundo semestre de cada ano. $\mathrm{O}$ ano seco apresentou temperaturas mais elevadas que o ano chuvoso. A amplitude térmica anual do ar foi de $2,54{ }^{\circ} \mathrm{C}$ em 2011 contra $4,73{ }^{\circ} \mathrm{C} \mathrm{em} \mathrm{2012.} \mathrm{Para} 2 \mathrm{~cm}$ de profundidade, as amplitudes térmicas anuais foram de 2,07 e $5,25^{\circ} \mathrm{C}$, respectivamente, para os dois anos, chuvoso e seco. Já para $20 \mathrm{~cm}$, as amplitudes 

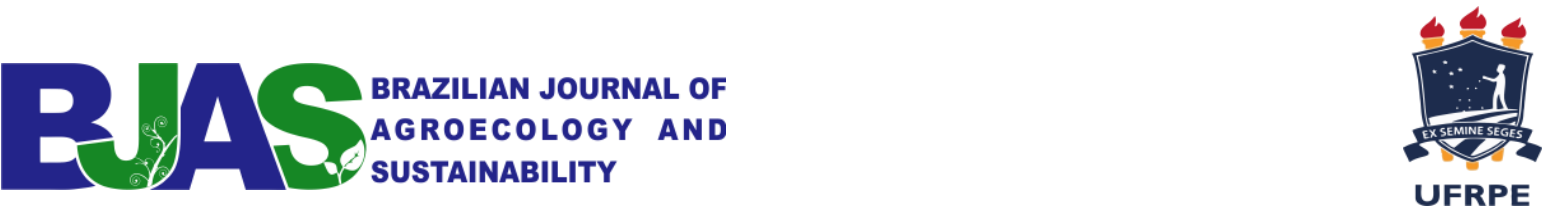

foram de $2,9{ }^{\circ} \mathrm{C}$ em 2011 , e de $4,8{ }^{\circ} \mathrm{C}$ em 2012. De todas as temperaturas medidas o valor máximo médio mensal registrado foi de $35,71{ }^{\circ} \mathrm{C}$ em outubro de 2012 . Corroborando esses fatos, Pereira, Angelocci e Sentelhas (2002) descreveram que a temperatura do ar influencia na temperatura das camadas superficiais do solo. Tal fato ressalta a influência da temperatura do ar sobre a dinâmica da temperatura no perfil do solo. Moura e Querino (2010) analisando a temperatura do solo em um manguezal tropical constataram que as temperaturas das camadas mais próximas à superfície foram um pouco mais elevadas do que as mais profundas no período de estiagem e esta relação se inverteu substancialmente no período chuvoso.

Dos parâmetros estudados, a radiação solar teve mais influência na menor profundidade $2 \mathrm{~cm}$ do que na maior de $20 \mathrm{~cm}$. Segundo Rao, Silva e Moreira (2005), as temperaturas nas camadas mais próximas à superfície (entre 2 e $10 \mathrm{~cm}$ ) variam mais facilmente em relação as demais, tendendo a serem mais amenas nos momentos em que o solo tem menos influência do calor oriundo da radiação e o oposto, onde há maiores temperaturas nas ocasiões em que existe maior influência deste calor.

\section{CONSIDERAÇÕES FINAIS}

Com bases nos dados apresentados observou-se que a temperatura do solo varia com a profundidade, com a camada mais superficial se aquecendo mais por receber maior incidência da radiação solar.

Em épocas de maior precipitação pluviométrica a temperatura do solo a $2 \mathrm{~cm}$ foi mais amena em relação a profundidade de $20 \mathrm{~cm}$. O período seco apresentou uma amplitude térmica maior quando comparada com o período chuvoso, além de maiores variações com a profundidade.

Com relação aos elementos meteorológicos analisados os maiores valores de temperatura do ar foram verificados em dias de maior incidência de radiação solar e maiores velocidades do vento, com comportamento inversamente proporcional à umidade relativa do ar.

A metodologia apresentada gerou equações que se ajustaram bem para o ano chuvoso, principalmente no primeiro semestre, apresentando restrições para os períodos secos. As equações ajustadas para a profundidade de $2 \mathrm{~cm}$ apresentaram melhores correlações do que aquelas geradas para $20 \mathrm{~cm}$ de profundidade.

A temperatura do solo depende de fatores meteorológicos como a radiação solar, temperatura do ar, precipitação pluviométrica, umidade relativa do ar e a velocidade do vento. 

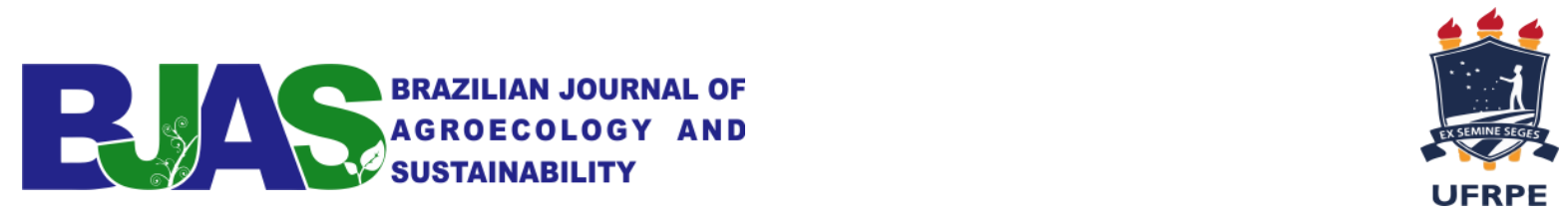

\section{REFERÊNCIAS}

Alfonsi, R. R., \& Sentelhas, P. C. (1996). Estimativa da temperatura do solo através da temperatura do ar em abrigo meteorológico. Revista Brasileira de Agrometeorologia, 4, $57-61$.

Alves, E. D. L., \& Biudes, M. S. (2012). Padrões da temperatura do ar e da umidade relativa: estudo de caso no campus de Cuiabá da Universidade Federal de Mato Grosso. Boletim de Geografia, 30, 5-16. Universidade Estadual de Maringá. Recuperado em http://dx.doi.org/10.4025/bolgeogr.v30i3.13114.

Alves, E. D. L., Santos, B. C., \& Neves, G. Z. F. (2016, outubro). A temperatura do ar na cidade de Iporá (GO): análise espacial em cidade de pequeno porte. Anais do Simpósio Brasileiro de Climatologia Geográfica, Goiânia,GO,Brasil, 12. Recuperado em http://www.abclima.ggf.br/sbcg2016/anais/arquivos/eixo_3/trabalho (8).pdf .

Ayoade, J. O. (2010). Introdução à climatologia para os trópicos (6a. ed.). Rio de Janeiro: Bertrand Brasil.

Bao, X., Zhu, X., Chang, X., Wang S., Xu, B., Luo, C., Zhang, Z., Wang, Q., Rui, Y., \& Cui, X. (2016). Effects of soil temperature and moisture on soil respiration on the Tibetan plateau. PLOS ONE, 11, 9-15.

Belan, L. L., Xavier, T. M. T., Torres, H., Toledo, J. V., \& Pezzopane, J. E. M. (2013). Dinâmica entre temperaturas do ar e do solo sob duas condições de cobertura. Revista Acadêmica Ciência Animal, 11, 147-154.

Campos, C. G. C., Vieira, H. J., Back, A. J., \& Silva, A. L. (2013). Fluxos de radiação solar global em vinhedos de altitude de São Joaquim-SC. Revista Brasileira de Fruticultura, 35, 722-729.

Carneiro, R. G., Moura, M. A. L., Silva, V. P. R., Silva Junior, R. S., Andrade, A. M. D., \& Santos, A. B. (2014). Variabilidade da temperatura do solo em função da liteira em fragmento remanescente de mata atlântica.

Empresa Brasileira de Pesquisa Agropecuária. (2013). Sistema brasileiro de classificação de solos (353 p.). Rio de Janeiro: Embrapa Solos.

Gasparim, E., Ricieri, R. P., Silva, S. L., Dallacort, R., \& Gnoatto, E. (2005). Temperatura no perfil do solo utilizando duas densidades de cobertura e solo nu. Acta Scientiarum Agronomy, 27, 107-115.

Geiger, R. (1980). Manual de micrometeorologia (556 p.). Lisboa: Calouste Gulbenkian. Recuperado de http://ecoqua.ecologia.ufrgs.br.

Medeiros, R. M., Tavares, A. L., Kascar, C. B., Silva, J. A. S., \& Silva, V. P. R. (2012). Metodologias de cálculo da temperatura média diária do ar: aplicação para os municípios de Parnaíba, picos e Gilbués, PI. Revista Brasileira de Agricultura Irrigada, 6, 283-295. 
Moura, M. A. L., \& Querino, C. A. S. (2010). Variação sazonal do fluxo de calor no solo dentro de um manguezal tropical. Revista Brasileira de Engenharia Agrícola e Ambiental, 14, 296-302.

Pereira, A. R., Angelocci, L. R., \& Sentelhas, P. C. (2007). Meteorologia Agrícola. Departamento De Ciências Exatas, 173.

Pereira, A. R., Angelocci, L. R., \& Sentelhas, P. C. (2002). Agrometeorologia: fundamentos e aplicações práticas.

Pillar, V. D. (1995). Clima e vegetação. Recuperado em http://ecoqua.ecologia.ufrgs.br.

Rao, T. V. R., Silva, B. B., \& Moreira, A. A. (2005). Características térmicas do solo em Salvador, BA. Revista Brasileira de Engenharia Agrícola e Ambiental, 9, 554-559.

Santos, D. M., Araujo, S. M., Araujo, K. D., Rosa, P. R. O., \& Pazera Júnior, E. (2009). Variabilidade temporal da radiação solar e insolação no Município de Araguaína - TO. Revista Raega, 18, 35-40.

Silva, M. F. A., Santos, M. N., Santos, C. E. L., \& White, B. L. A. (2016). Avaliação da temperatura do solo, temperatura do ar e umidade relativa do ar em uma clareira de mata atlântica no município de São Cristóvão, Sergipe, Brasil. Agroforestalis News, 1, 58-62.

Tavares, V. C., Arruda, I. R. P., \& Silva, D. G. (2019). Desertificação, mudanças climáticas e secas no semiárido brasileiro: uma revisão bibliográfica. Geosul, 34, 385-405.

\section{AGRADECIMENTOS}

A Universidade Federal Rural do Semi-Árido; Universidade Federal Rural de Pernambuco; Programa de Pós-Graduação em Engenharia Agrícola; O presente trabalho foi realizado com apoio da Coordenação de Aperfeiçoamento de Pessoal de Nível Superior - Brasil (CAPES) - Código de Financiamento 001; Conselho Nacional de Desenvolvimento Científico e Tecnológico. 